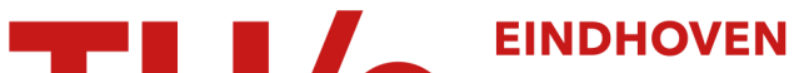 UNIVERSITY OF TECHNOLOGY
}

\section{Efficient dewatering of waterworks sludge by electroosmosis}

Citation for published version (APA):

Buijs, P. J., Diemen, van, A. J. G., \& Stein, H. N. (1994). Efficient dewatering of waterworks sludge by electroosmosis. Colloids and Surfaces A: Physicochemical and Engineering Aspects, 85(1), 29-36.

https://doi.org/10.1016/0927-7757\%2894\%2902741-2, https://doi.org/10.1016/0927-7757(94)02741-2

DOI:

10.1016/0927-7757\%2894\%2902741-2

10.1016/0927-7757(94)02741-2

Document status and date:

Published: 01/01/1994

\section{Document Version:}

Publisher's PDF, also known as Version of Record (includes final page, issue and volume numbers)

\section{Please check the document version of this publication:}

- A submitted manuscript is the version of the article upon submission and before peer-review. There can be important differences between the submitted version and the official published version of record. People interested in the research are advised to contact the author for the final version of the publication, or visit the $\mathrm{DOI}$ to the publisher's website.

- The final author version and the galley proof are versions of the publication after peer review.

- The final published version features the final layout of the paper including the volume, issue and page numbers.

Link to publication

\section{General rights}

Copyright and moral rights for the publications made accessible in the public portal are retained by the authors and/or other copyright owners and it is a condition of accessing publications that users recognise and abide by the legal requirements associated with these rights.

- Users may download and print one copy of any publication from the public portal for the purpose of private study or research.

- You may not further distribute the material or use it for any profit-making activity or commercial gain

- You may freely distribute the URL identifying the publication in the public portal.

If the publication is distributed under the terms of Article 25fa of the Dutch Copyright Act, indicated by the "Taverne" license above, please follow below link for the End User Agreement:

www.tue.nl/taverne

Take down policy

If you believe that this document breaches copyright please contact us at:

openaccess@tue.nl

providing details and we will investigate your claim. 


\title{
Efficient dewatering of waterworks sludge by electroosmosis
}

\author{
P.J. Buijs ${ }^{1}$, A.J.G. Van Diemen, H.N. Stein* \\ Laboratory of Colloid Chemistry, Eindhoven University of 'I echnology, P.O. Box 513, 5600 MB Eindhoven, \\ The Netherlands
}

(Received 4 July 1993; accepted 24 December 1993)

\begin{abstract}
Electroosmotic dewatering of water treatment process sludge, in which a relatively high specific resistance causes difficulties with regard to water removal, is described. The dewatering can be both accelerated and made economically more attractive by additives which increase the absolute value of the $\zeta$ potential but do not lead to stable suspensions. An increase in $\zeta$ potential means an increase in electroosmotic water transport; simultaneously electric charges on the filter repel particles with electrical charges of the same sign, which causes a decrease in the clogging of the filtration material. Best results show an increase in final dry solid content from $4 \%$ (by weight) by pressure filtration only, to $16 \%$ (by weight) by a combination of electroosmosis with pressure filtration.
\end{abstract}

Key words: Dewatering; Electroosmosis; Waterworks sludge

\section{Introduction}

Industrialized societies at present face a problem of increasing importance: disposal of sludges. These originate during water treatment (e.g. when making surface water fit for drinking water), on treatment of sewage, or on dredging harbours.

The problem is becoming urgent because of three cooperative effects: the increasing quantities of contaminated sludge, the more stringent environmental legislation and the decreasing availability of disposal sites. Most sludges are contaminated by either organic components or by heavy metals to such a degree that the job of finding disposal sites for them is not an easy one.

One of the key problems in handling the sludges is the reduction of water content. Even a sludge which does not cause any possible toxic problems

*Corresponding author.

${ }^{1}$ Present address: KIWA N.V. Research and Consultancy, P.O. Box 1072, 3430 BB Nieuwegein, The Netherlands. has to be dewatered before disposal. Treatment of sludge to remove contaminants (e.g. arsenic removal), or sludge treatment for beneficial application requires reduction of the water content. Most processes involved in recycling solid materials from sludges, for example by melting them into a glass or processing them into a ceramic brick, start by drying the sludge; a high water content makcs this stcp expensive because of the large enthalpy of evaporation of water. However, frequently separation of solids in sludges from water is not easy to perform in an economically feasible way: filtration sometimes does not lead to solids contents higher than about $4 \%$ (by weight), especially when the sludge contains large quantities of materials such as algae or aluminium hydroxide flocs.

In addition, removal of part of the water may be required for the handling of sludges. Thus, a typical sludge is obtained when making drinking water from surface water by adding polyaluminium 
chloride (PAC) to the initial water, for coagulating suspended particles; the coagulates are removed by flotation and have a solids content between 1 and $1.5 \%$ (by weight). After adding a polymer flocculant, the solids content of the sludge can be increased to $4-5 \%$ (by weight) by filtration without applying pressure; however, the resulting sludge is still too thin to be handled in a filter belt press.

In this situation, we thought it useful to investigate the possibilities of applying electroosmotic dewatering. The method had been introduced in 1900 [1] but never had a breakthrough for largescale application except on occasions when economic aspects are of second-order importance, such as in the case of building of shelters for vessels in war time [2]. In most cases, the cost of electroosmotic dewatering is too high for large-scale use [3]. However, in recent times a revival of interest in this dewatering method has been seen: dewatering of coal washery tailings has been reported [4-6], and new electrode materials are being developed [7]. In most cases, increased efficiency of electroosmotic dewatering is looked for by changes in electrode manufacture (either shape, or material; see for example Ref. 7). However, it has been shown recently $[8,9]$ that the economics of electroosmotic dewatering can be influenced considerably by studying the colloid chemistry of the process. Thus $\zeta$ potentials of large absolute value can be achieved by adding surfactants; this makes dewatering more rapid and economically attractive but may lead to stable dispersions which tend to block solid/liquid separation. The present communication is based on experiments intended to look for an additive which imparts to the solid particles present a large $\zeta$ potential without impairing coagulation. As such, a polyelectrolyte was investigated, in spite of the $\zeta$ potential tending to be lowered (in the absolute sense) on polymer addition because of a shift of the electrokinetic slipping plane away from the particle surface [10]. The adsorption of the electrically charged polymer, however, increases the (absolute) $\zeta$ potential, but by adding a polyelectrolyte in a concentration range leading to bridging coagulation, we expected to find increased $|\xi|$ values combined with coagulation, corresponding to an optimum between two counteracting mechanisms.

\section{Experimental}

\section{Materials}

Sludge "WRK" was obtained on water treatment (river Rhine) after addition of $\mathrm{FeCl}_{3}$ and $\mathrm{NaOH}$ to surface water. The initial solids content was $10 \%$ (by weight).

Sludge "WOT" was obtained on addition of poly(aluminium chloride) to surface water (Twente canal). The initial dry solids content was $1.5 \%$ (by weight); at this stage the sludge had a filtration resistance of $78 \times 10^{-12} \mathrm{~m} \mathrm{~kg}^{-1}$.

Polyelectrolyte 1 (indicated as poly1) was Magnafloc 155 (from Allied Colloids), a copolymer of sodium acrylate and acrylamide; average molecular weight $(10-15) \times 10^{6}$.

Polyelectrolyte 2 (indicated as poly 2 ) was Superffoc A130 (from American Cyanamid Co.), a copolymer of sodium acrylate and acrylamide; average molecular weight $(6-8) \times 10^{6}$.

Concentration of polyelectrolytes is expressed in kilograms per $1000 \mathrm{~kg}$ of solid in the sludge, or as kilograms per tonne sludge.

\section{Apparatus}

The $\zeta$-potential measurements were performed with a MATEC ESA 8000 apparatus (measuring electrosonic amplitude (ESA), i.e. the amplitude of the sonic signal resulting from movement of a charged particle and its counterion atmosphere in an alternating electrical field). In contrast with electrophoresis, this method can be applied in concentrated suspensions; however, the interpretation of the signal is complicated by the influence of particle size and by mutual interaction between the particles [11]. In the present case this proved to be an advantage because the change in average particle size by coagulation was traced in the ESA signal. An important advantage of this method is 
that $\zeta$ measurements can be performed during titration.

\section{Methods}

The occurrence of coagulation on polymer addition was followed by measuring (a) the capillary suction time (CST) by means of a CST apparatus (TRITON CST FILTRABILITY TESTER MODEL 200), and (b) the torque exerted on the stirrer of the MATEC apparatus, when rotating with constant speed, by means of a COESFELD VISCOMIX torque/rotation rate recorder. For comparison with other mixing geometries we mention the dimensions of the measuring beaker of the MATEC apparatus (inner diameter $80 \mathrm{~mm}$, height $80 \mathrm{~mm}$ ) and of the stirrer (propeller type, $50 \mathrm{~mm}$ outer diameter, consisting of three metal blades of breadth $16 \mathrm{~mm}$ ). Stirring was performed at 100 , 250 or $500 \mathrm{rev} \mathrm{min}^{-1}$.

Batchwise electroosmotic dewatering was performed in an apparatus shown in Fig. 1, in which

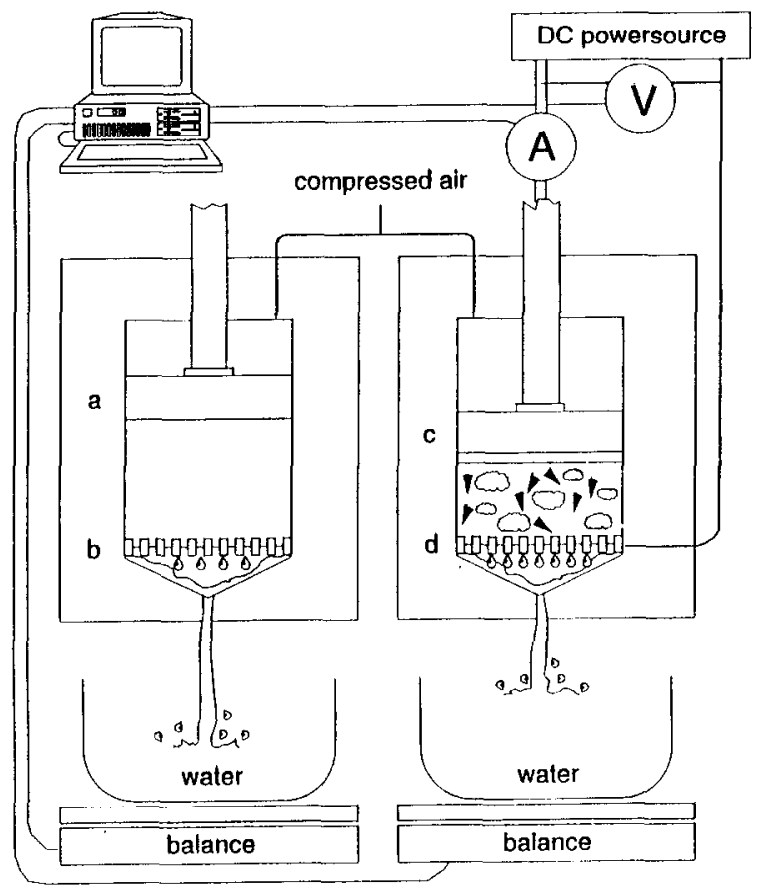

Fig. 1. Batchwise electroosmotic dewatering equipment; a, b, c and $\mathrm{d}$ are stainless steel electrodes. both a pressure difference and an electric field could be applied over a sediment. When applying an electric field over the sediment, the piston (stainless steel) was used as anode, the filter plate as cathode. During clectroosmosis, the clectrical potential difference between the electrodes was kept constant, leading to an increasing effective field strength in the course of the process. Conditions for batchwise experiments were chosen so as to correspond best to large scale experiments, which had to be restricted for practical reasons to the use of polyelectrolyte 1 with sludge "WRK", and polyelectrolyte 2 with sludge "WOT".

Continuous electroosmosis was performed on two apparatuses: (a) a pilot plant apparatus of disposition and size as shown in Fig. 2(a); (b) an industrial dewatering filter belt gravity thickener (Voest Alpine). This apparalus was adapted for performing electroosmosis by placing a perforated

(a)

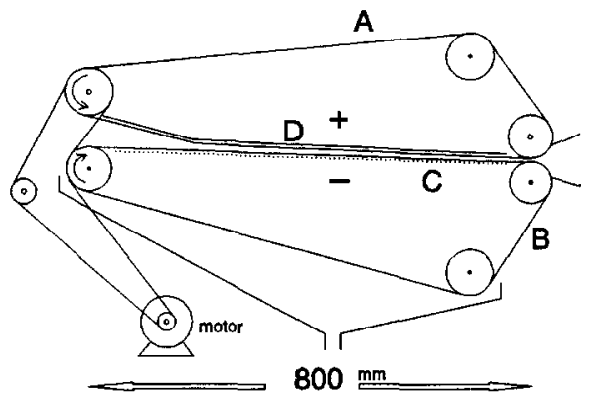

(b)

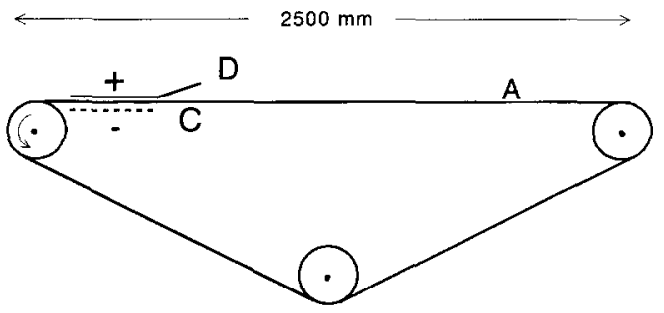

Fig. 2. (a) Pilot scale electroosmotic dewatering equipment: A and $B$ are polyester filter belts (mesh size $0.5 \mathrm{~mm}$ ); $\mathrm{C}$ is a perforated stainless steel plate used as cathode; $D$ is a stainless steel plate used as anode. Breadth of the filter belts is $500 \mathrm{~mm}$. (b) Industrial dewatering filter belt gravity thickener. $\mathrm{A}$ is a polyester filter belt (mesh size $0.39 \mathrm{~mm}$, breadth $1250 \mathrm{~mm}$; $\mathrm{C}$ is a perforated stainless steel plate used as cathode and $D$ is a stainless steel plate used as anode (length $500 \mathrm{~mm}$, breadth $1000 \mathrm{~mm}$ ). 
steel plate (acting as cathode) beneath the filter belt, and using a stainless steel pressure plate (isolated from the frame of the thickener) at the topside of the sludge, acting as an anode.

\section{Results and discussion}

\section{Influence of conditions by polyelectrolyte addition}

Figure 3 shows the effect of the addition of $0.1 \%$ (by weight) polyelectrolyte 1 on the electrosonic amplitude of a $10 \%$ (by weight) suspension of sludge "WRK", at different stirring speeds of the stirrer. It is seen that the stirring speed greatly influences the ESA. The simplest curve is obtained during high speed stirring: the result is similar to the one obtained on addition of a surfactant (e.g. sodium dodecylbenzenesulphonate).

The ESA acquires larger values which are interpreted as due to an increase in $|\zeta|$ values. Separate measurements showed that the particles in the original sludge had a negative $\zeta$ potential, varying between -10 and $-18 \mathrm{mV}$ measured by electrophoresis, while this sludge was stable against coagulation. The curve therefore indicates that adsorption of the polyanions of the polyelectrolyte on the particles does not decrease the $|\zeta|$ values but on the contrary increases them. With lower stirring speeds, however, the ESA showed a more complicated course, indicating lowering of the ESA at a certain polymer concentration. Since decrease

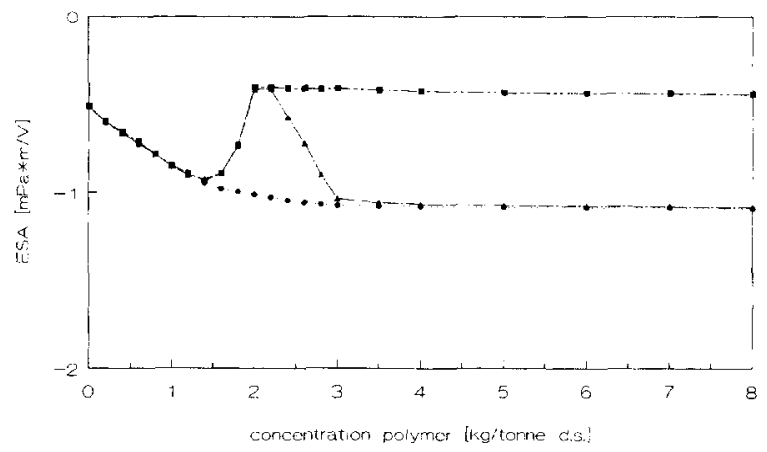

Fig. 3. Electrokinetic sonic amplitude vs. polyelectrolyte concentration at different stirrer speeds ("WRK" sludge with poly1): $\boldsymbol{\square}, 100 \mathrm{rev} \min ^{-1} ; \boldsymbol{\Lambda}, 250 \mathrm{rev} \min ^{-1} ; \boldsymbol{\bullet}, 500 \mathrm{rev} \min ^{-1}$. of the absolute value of $\zeta$ potential by addition of polyelectrolyte in the present case is unlikely in view of the data at higher stirring speeds, this decrease in ESA is explained best by an increase of the effective particle size through coagulation. The curves indicate that at low stirring speeds, because of incomplete homogenization on polyelectrolyte addition, the polyelectrolyte is not distributed homogeneously over the surfaces of the solid particles and this causes bridging flocculation.

This interpretation is confirmed by separate measurements of CST and ESA, and by simultaneous measurements of ESA and the relative torque experienced by the stirrer (Figs. 4 and 5 respectively).

The CST has a minimum, and the torque experienced by the stirrer has a maximum at the same polyelectrolyte concentration at which the ESA has a minimum value. Both the minimum CST

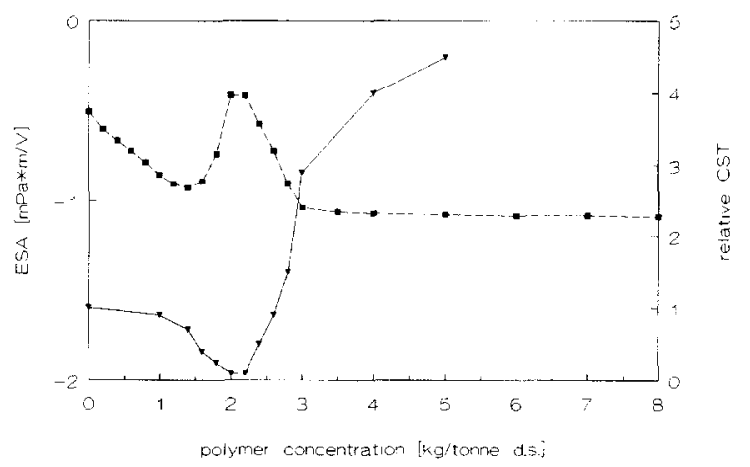

Fig. 4. ESA ( $\mathbf{\square})$ and CST ( $\mathbf{\nabla}$ ) vs. polymer concentration ("WRK" sludge with poly1).

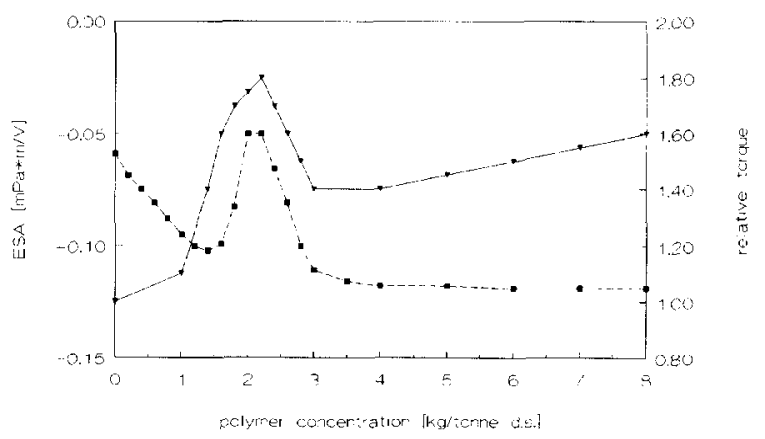

Fig. 5. ESA ( $\square$ ) and relative torque ( $\boldsymbol{\nabla})$ vs. polymer concentration ("WOT" sludge with poly2). 
(indicating strong flocculation), and the maximum torque (indicating mutually connected solid particles) agree with pronounced coagulation at the polyelectrolyte concentration concerned. It should be noted, however, that such pronounced coagulation is only observed under specified mixing conditions. Measurement of the ESA is a convenient way of determining the optimum conditions (flocculant concentration, pretreatment procedure) for any sludge.

These data show that addition of a polyelectrolyte may increase the absolute value of the $\zeta$ potential while effecting coagulation, thus proving that an optimum between the two counteracting mechanisms indicated in the introduction can be achieved.

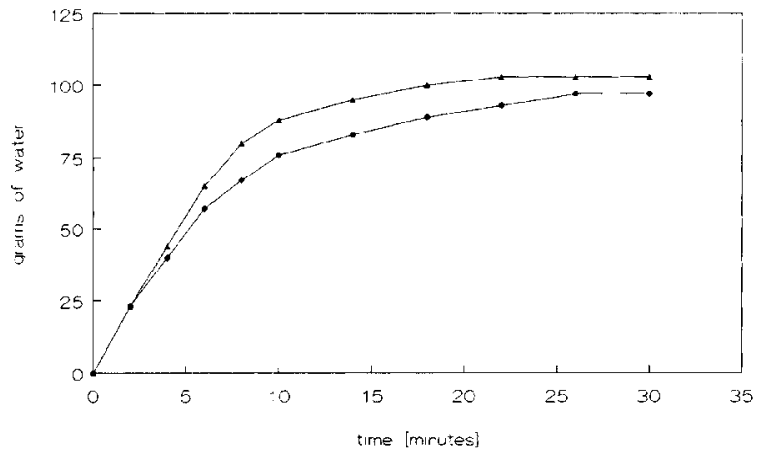

Fig. 6. Dewatering curves ("WRK" sludge with poly1; $p=3$ bar; $10 \mathrm{~V}$; initial electrode distance, $2 \mathrm{~cm}$ ): $\boldsymbol{\Delta}$, with electroosmosis, without electroosmosis.

\section{Batchwise electroosmotic dewatering}

A typical experiment is shown in Fig. 6. The switching on of an electrical current is seen to lead to a pronounced increase in water extraction rate.

Table 1 compares results obtained without an electrical field, with results obtained by switching on an electric field directly at the start of the dewatering (voltage difference $20 \mathrm{~V}$, initial electrode distance $40 \mathrm{~mm}$ ). The concentration of the additive is expressed in kilograms polymer per tonne dry solids. Solids content is expressed as percentage by weight. Final 1 was determined after applying pressure only, and final 2 after applying both pressure and electrical field during the dewatering.

It is seen that especially intermediate concentrations of additive lead to a high final solid content of the sludge, both in the absence and in the presence of an electrical field. However, the application of an electrical field in all cases increases the final solid content. For comparison with water removal by thermal treatment, we mention that the heat of evaporation of water is $2442 \mathrm{~kJ} \mathrm{~kg}^{-1}$.

The statement in the previous paragraph on the influence of the concentration of additives agrees with the dala shown in Figs. 4 and 5. According to these experiments an intermediate concentration of polyelectrolyte leads to a small ESA valuc, a

Table 1

Batchwise electroosmotic dewatering experiments

\begin{tabular}{|c|c|c|c|c|c|}
\hline $\begin{array}{l}\text { Sludge } \\
\text { type }\end{array}$ & $\begin{array}{l}\text { Additive } \\
\text { type (conc.) }\end{array}$ & $\begin{array}{l}\text { Solid content, } \\
\text { initial }\end{array}$ & $\begin{array}{l}\text { Solid content, } \\
\text { final } 1\end{array}$ & $\begin{array}{l}\text { Solid content, } \\
\text { final } 2\end{array}$ & $\begin{array}{l}\text { Electrical energy } \\
\text { consumption }{ }^{1}\end{array}$ \\
\hline \multirow[t]{3}{*}{ WRK } & None & 10 & 33 & 42 & 56 \\
\hline & poly1 (2) & 10 & 45 & 57 & 25 \\
\hline & poly1 (5) & 10 & 30 & 37 & 70 \\
\hline \multirow[t]{3}{*}{ WOT } & None & 1.5 & 12 & 19 & 35 \\
\hline & poly $2(2)$ & 1.5 & 16 & 26 & 27 \\
\hline & poly 2 (5) & 1.5 & 12 & 20 & 45 \\
\hline
\end{tabular}

${ }^{1}$ In $\mathrm{kJ} \mathrm{kg}^{-1}$ water withdrawn. 
large torque on the stirrer, and a short CSI. Ihus such intermediate concentrations are most favourable for coagulation. Similar conditions also are most favourable for dewatering.

Figure 7 shows the influence of pressure difference and electrical potential difference between the electrodes on the final dry solid content of WRK sludge. It is seen that although the final dry solid increases with increasing potential difference between the electrodes, a potential difference of $20 \mathrm{~V}$ suffices for obtaining the main effect. The electrical work per kilogram of removed water is shown in Fig. 8. It is seen that this is not dependent on the applied pressure, and that an increase in applied voltage results in a larger energy consumption. Nevertheless, because of the more rapid attainment of the dry solid content mentioned, for

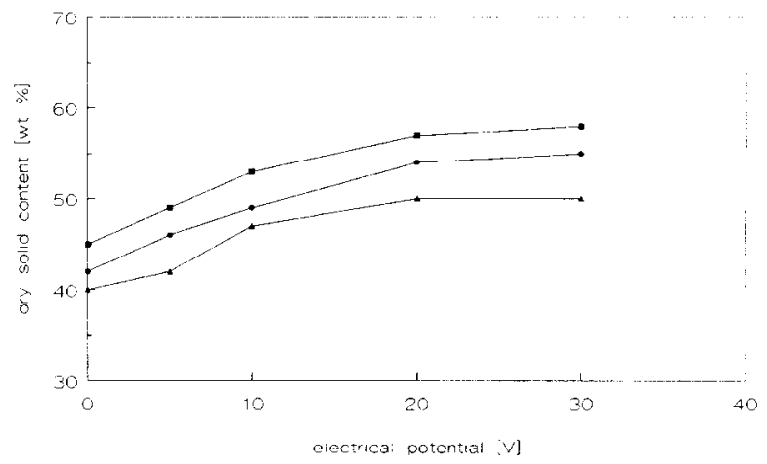

Fig. 7. Final dry solid content (\% by weight) vs. electrical potential at different initial pressures ("WRK" sludge with poly1): $\boldsymbol{\Lambda}, 1$ bar;, 2 bar: $\mathbf{0}, 3$ bar.

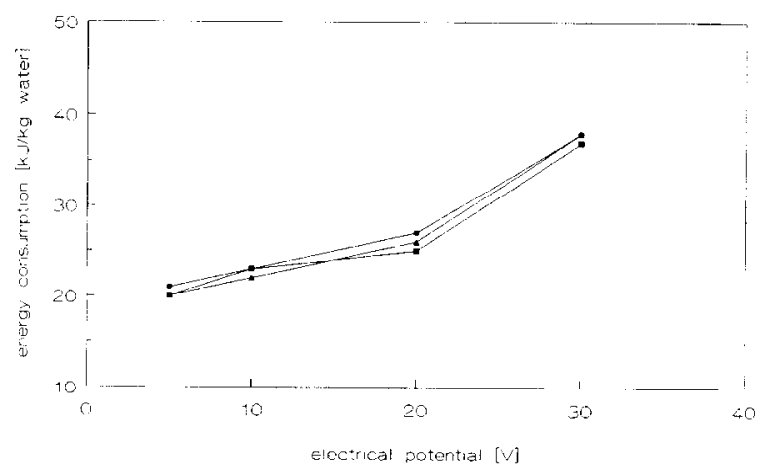

Fig. 8. Energy consumption ( $\mathrm{kJ} \mathrm{kg}^{-1}$ water) vs. electrical potential at different pressures: $\boldsymbol{\Lambda}, 1$ bar;, 2 bar; $\mathbf{\square}, 3$ bar. part of the experiments in Table 1, the use of a higher voltage may be advantageous from a practical point of view.

It should be noted that during dewatering the electrode distance decreases, leading (under the conditions of constant voltage difference between the electrodes) to an increasing field strength during the electroosmosis. Figures 9 and 10 show the influence of initial electrode distance at different applied voltages on final dry solid content and energy consumption per kilogram withdrawn water respectively.

A smaller electrode distance is an advantage in both cases; it will, however, lead to a decreased capacity and thus to higher investment costs.

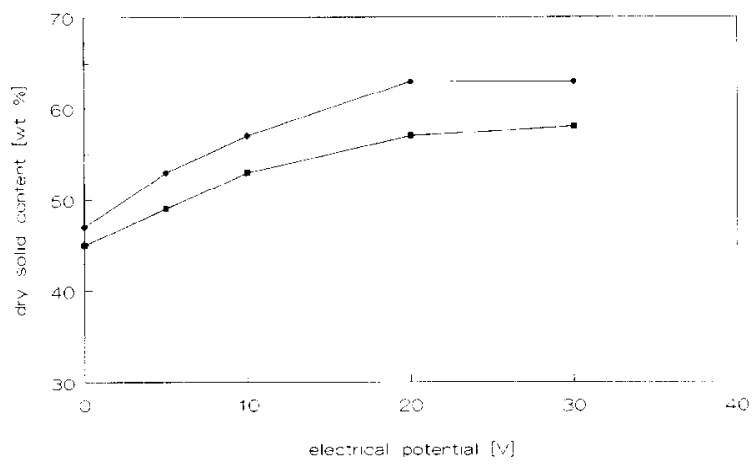

Fig. 9. Dry solid content ( $\%$ by weight) vs. electrical potential at different initial electrode distances:, $2 \mathrm{~cm} ; \mathbf{\square}, 4 \mathrm{~cm}$.

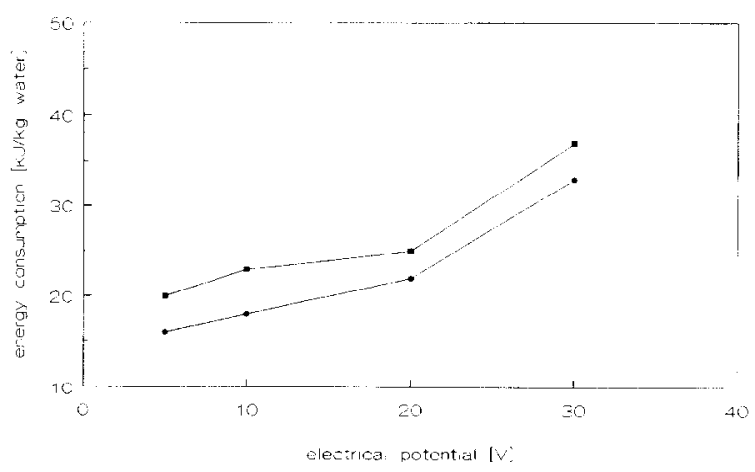

Fig. 10. Energy consumption ( $\mathrm{kJ} \mathrm{kg}^{-1}$ water) vs. electrical potential at different electrode distances; $2 \mathrm{~cm} ; \boldsymbol{\square}, 4 \mathrm{~cm}$. 


\section{Continuous electroosmosis}

Experiments with the pilot scale press

Using the pilot scale press, experiments were performed on WOT sludge withoul pretreatment (flotation sludge of $1.5 \%$ by weight) and on WOT sludge preconditioned with $2 \mathrm{~kg}$ poly 2 per tonne dry solid and dewatered on the WOT gravity belt thickener. Table 2 shows some results relating to WOT sludge treated by poly 2 at this level. For comparison with other dewatering methods, the electrical energy consumption has been expressed in this case in kilowatt hours per tonne sludge.

An advantageous effect found is that the filter belt is much less likely to become clogged by the deposited solids when an electric field was applied. This is illustrated in Fig. 11. Apparently the contact between the cathode and the solid particles is impeded by the equality of sign of their respective electric charges; in other words the particles are repelled by the cathode. The decrease in filter clogging can also be ascribed to a reconstruction of the floc structure in the vicinity of the electrodes. This might be caused on the one hand by the rupture of the flocs by the pressure plate and on the other hand by the changed aqueous phase (the filtrate had a $\mathrm{pH}$ of about 11, indicating that electrode processes at the cathode definitely change the conditions in the aqueous phase).

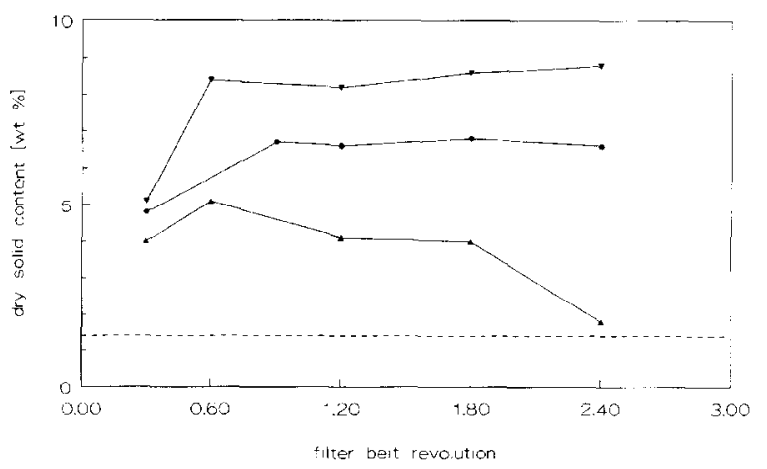

Fig. 11. Dry solid content (\% by weight) vs. number of filter belt revolutions at different electrical potentials: $\boldsymbol{\Lambda}, 0 \mathrm{~V}$; - $10 \mathrm{~V} ; \boldsymbol{\nabla}, 20 \mathrm{~V} ;-$, incoming sludge.

\section{Large-scale experiments}

These were performed with the WOT sludge. The sludge was preconditioned by poly $2(2.5 \mathrm{~kg}$ per tonne dry solid). The mixing intensity of polymer and sludge was increased up to a point where compact flocs were formed. The dry solid content reached after treatment in the filter belt thickener without an electrical field was increased from $4.5 \%$ to $7 \%$ (by weight) by the application of a pressure plate. When applying an electrical potential of $30 \mathrm{~V}$, using the pressure plate as anode, the dry solid content increased steeply to about $14 \%$ (by weight).

Another effect that was observed (albeit not

Table 2

Pilot scale electroosmotic dewatering experiments

\begin{tabular}{llclll}
\hline Exp. & Initial $^{2}$ & Piess $^{3}$ & $\begin{array}{l}\text { Press }+ \\
\text { electroosmotic } \\
\text { dewatering }\end{array}$ & $\begin{array}{l}\text { Applied } \\
\text { potential } \\
\text { (v) }\end{array}$ & $\begin{array}{l}\text { Energy } \\
\text { consumption } \\
\left(\mathrm{kWh} \mathrm{t}^{-1}\right)\end{array}$ \\
\hline 1 & 1.4 & 4.0 & 6.8 & 10 & 1.7 \\
1 & 1.4 & 4.0 & 8.8 & 20 & 1.9 \\
2 & 4.9 & 7.8 & 12.2 & 10 & 0.3 \\
2 & 7.0 & 10 & 19 & 20 & 0.3 \\
\hline
\end{tabular}

Residence time was 20 min.

${ }^{1} 1$, WOT sludge without treatment; 2 , WOT sludge with treatment.

${ }^{2}$ Initial dry solid content ( $\%$ by weight), prior to dewatering.

${ }^{3}$ Dry solid content ( $\%$ by weight) after dewatering, without using electroosmosis.

${ }^{4}$ Dry solid content (\% by weight) after dewatering, applying electroosmosis. 
quantitatively measured) was that the turbidity of the water running through the filter was much improved on application of an electrical field. This is in agreement with the repulsion of the negatively charged particles in the cathode region.

The energy consumption of the electroosmotic process was $0.6 \mathrm{kWh} \mathrm{m}^{-3}$ sludge, and the final solid content of the sludge on large scale application of electroosmosis was $14 \%$ (by weight).

However, it should be noted that these values may differ for different sludges. For any sludge, the optimum conditions can be located rapidly by ESA measurements complemented by separate CST and stirring resistance measurements.

It is not clear at present what exactly the role is of the increase of the $|\xi|$ values at small polyelectrolyte concentrations which has been observed. At such concentrations, dewatering is improved by polyelectrolyte addition but this can be explained by stimulation of coagulation. Increasing $|\zeta|$ values leads to a larger driving force for electroosmosis, and to protection of the electrodes against coverage by solid particles. Both effects act favourably on dewatering. However, too large $|\zeta|$ values impair the dewatering. This can be ascribed to counteracting coagulation and to formation of a dense filter cake.

\section{Conclusions}

Polymers can cause bridging coagulation in a stable suspension in spite of increasing the absolute values of the $\zeta$ potential. This makes it possible to increase the efficiency of electroosmotic dewatering, without leading to compact filter cakes or blocking of filters, by a higher driving force for electroosmosis and a larger repulsion between the negatively charged sludge particles and the negatively charged dewatering electrode. Electroosmotic dewatering on commercial sludges can be performed, both on pilot plant scale and on real process scale. Energy consumptions in the range $20-40 \mathrm{~kJ} \mathrm{~kg}^{-1}$ removed water have been found. This is low in comparison with the energy consumption by evaporation $\left(2442 \mathrm{~kJ} \mathrm{~kg}^{-1}\right.$ removed water). In addition, the filtrate shows much less turbidity when electroosmosis is practised.

\section{Acknowledgement}

The authors want to express their thanks to Waterleidingbedrijf Oost-'Twente, for cooperation and the use of their facilities.

\section{References}

1 B. Schwerin, Ger. Patents 124,509; 124,510; 128,085, 1900; 132,932 1901: 150,069 1902.

2 L. Casagrande, Geotechnique, 1 (1949) 159.

3 J. Greyson and H.H. Rogers, Dewatering of sewage sludge by electroosmosis, in S.H. Jenkins (Ed.), Advances in Water Pollution Research: Proceedings of the 5th International Conference 1970, Vol. 1, Pergamon, Oxford, 1971. pp. 11-26, 1-15.

4 N.C. Lockhart and R.E. Stickland, Powder Technol., 40 (1984) 215 .

5 N.C. Lockhart and R.E. Stickland, Colloids Surfaces, 6 (1983) 229.

6 N.C. Lockhart, Int. J. Miner. Process., 10 (1983) 131.

7 Documentation on electrodes provided by Tokai Carbon Co., Ltd.

8 A.J. Kuin, H.J.A. Ogrinc and H.N. Stein, Colloids Surfaces, $27(1987) 65$

9 A.J.G. van Diemen, M.J.H. de Vet and H.N. Stein, Colloids Surfaces, 85 (1989) 57.

10 J. Ossowski, Pr. Nauk. Inst. Geotech. Polytcch. Wroclaw., $11(1972) 63$.

11 R.J. Goetz and M.S. El-Aasser, J. Colloid Interface Sci., 150 (1992) 436 . 